\title{
Pfizer advertises smoking cessation drug despite health warnings
}

$\mathrm{P}$ harmaceutical giant Pfizer Canada is using a national advertising campaign to persuade Canadians who want to quit smoking to use its smoking cessation drug varenicline (Champix), despite a recent study linking it to serious cardiovascular events.

The firm is precluded from doing so in the United States, which has tougher advertising standards than Canada, and some experts argue that the Canadian campaign should be halted by either the government or the firm itself. Doing so, they say, would be in accord with principles that the firm's US parent must abide by as a result of regulations that prohibit manufacturers from using "reminder ads" to advertise drugs that carry black box warnings.

Pfizer Canada rolled out its varenicline campaign, "in a punctual way," in January 2011. The campaign, which includes billboards, print and digital advertising, is intended "to encourage an open dialogue between a patient and his/her physician," says Andrea Gilpin, a spokesperson for Pfizer Canada.

It features "reminder ads," a type of direct-to-consumer advertisement that assumes people are already familiar with the condition for which varenicline is prescribed. They do not describe how well the drug works or its potential risks.

The ads carry the tag line "I did it!" and highlight varenicline's brand name and a website, while advising people to talk to their doctor or health care professional about the drug's merit.

Pfizer has since continued to expand the forums in which it is using the ads, despite research that indicates people who take varenicline are more likely to experience an irregular heartbeat, heart attack or stroke than people who take a placebo (www.cmaj.ca/lookup/doi /10.1503/cmaj.110218).

The meta-analysis of data from 14 double-blind randomized clinical trials

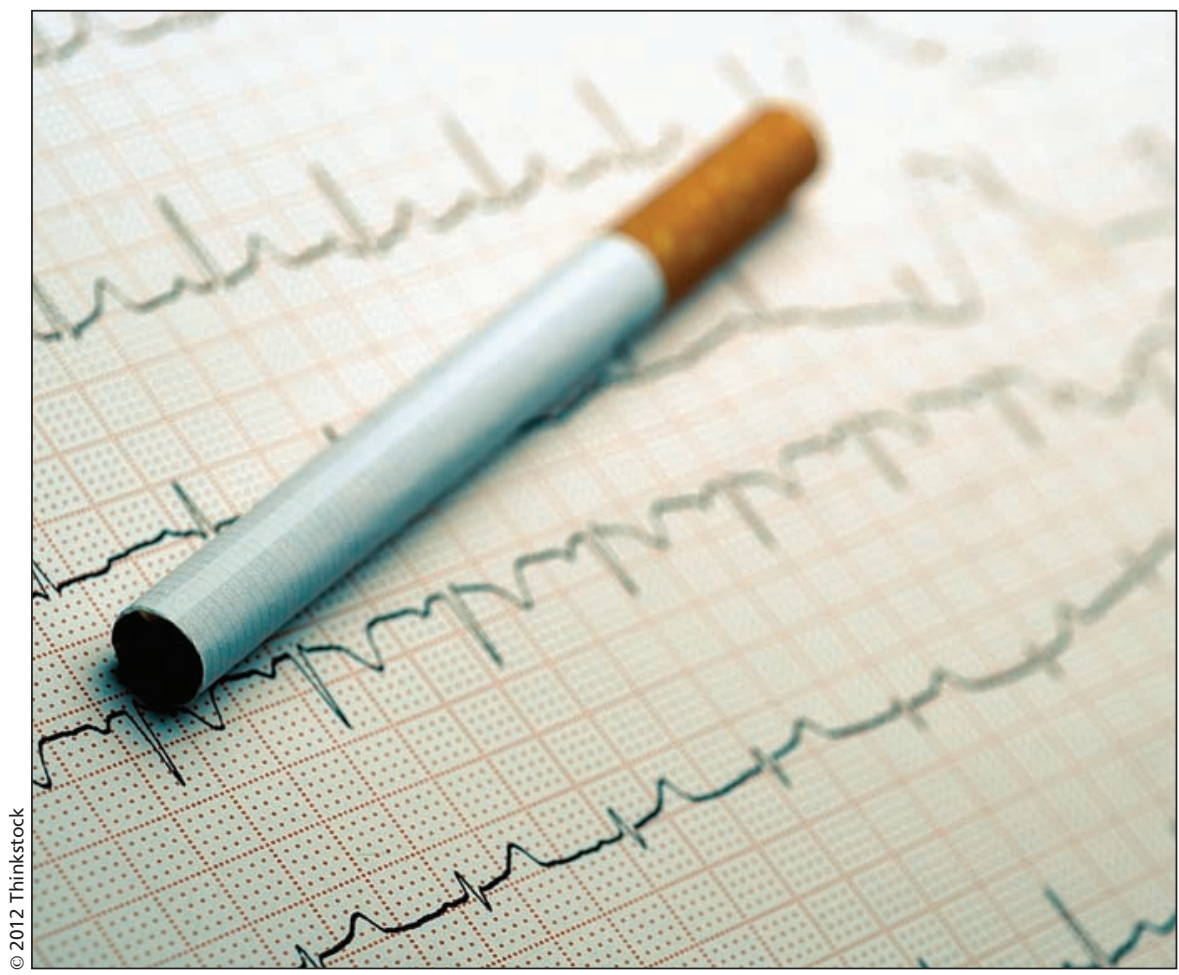

A meta-analysis of data from 14 double-blind randomized clinical trials found that people taking varenicline had a $72 \%$ higher risk of adverse heart-related events than those on placebo.

found that people taking varenicline had a $72 \%$ higher risk of adverse heartrelated events than those on placebo. It prompted Health Canada to launch a safety review of the drug and issue a warning advising consumers of "the possibility of a slightly increased risk of heart-related side effects in patients who have cardiovascular disease."

Health Canada has not yet concluded its review.

Varenicline, meanwhile, already carries warnings, as a result of Health Canada advisories issued in 2008, 2009 and 2010, concerning potential serious neuropsychiatric adverse events such as depression, agitation, hostility, behaviour changes, suicidal ideation and suicide. The regulator alerted health care professionals to those potential adverse effects, using what is known as a "Dear Doctor" let- ter, while posting warnings directed at consumers on the agency's website.

In the US, the Food and Drug Administration compelled varenicline manufacturers to use the agency's most serious level of "black box" warning because of those neuropsychiatric adverse events.

"The rationale is that because companies are not required to state risk information in reminder ads, it's a public safety concern that people are not getting the warnings about the serious risks that you get from a drug with a black box warning," says Barbara Mintzes, a professor of epidemiology and an assistant professor in anesthesiology, pharmacology and therapeutics at the University of British Columbia in Vancouver.

The fact that Canada does not have the same advertising standards, and Health Canada has less than one full- 
time position devoted to regulating pharmaceutical promotion, should not absolve Pfizer from the responsibility to advertise products in a manner consistent with the ethical standards in the home nation of its parent, Mintzes argues. "Because we have a more lax approach to enforcement in Canada, it doesn't mean that a corporation should be advertising in a way that, on safety grounds, it's not allowed to advertise in its country of origin."

Mintzes was "completely horrified" to see varenicline ads on a billboard near her Vancouver home because of the serious nature of the adverse events associated with the medication.

"One of my concerns is that often, when you have a safety concern about a medicine, it will affect sales volumes, and rightly so," Mintzes says. "When people see this billboard and it's just a claim of easy success in quitting smoking from using this product, it doesn't give you any idea of how this compares to other alternatives that might be around to quit smoking."

Advertising Standards Canada, which must clear such advertisements before they can be aired or published, has reviewed and approved the varenicline campaign, Gilpin writes in an email.

Health Canada has not received any complaints about the campaign, spokesperson Olivia Caron writes in an email.

In 2010, retail pharmacists dispensed $\$ 58.4$ million worth of varenicline in Canada, down from $\$ 64.9$ million in 2009, according to IMS Brogan, a health services consulting firm. The firm has not yet analyzed 2011 sales figures. - Laura Eggertson, Ottawa, Ont.

CMAJ 2012. DOI:10.1503/cmaj.109-4087 